\author{
MONIKA GRZELKA \\ AGNIESZKA KULA
}

Uniwersytet im. A. Mickiewicza w Poznaniu

\title{
Rewolucja czy ewolucja? Przemiany polskiego newsa telewizyjnego
}

O społecznej istotności telewizyjnego newsa mogą świadczyć badania ilościowe i jakościowe - prowadzone równolegle. Analizy firmy YouGov, przeprowadzone na początku 2014 roku na zlecenie Instytutu Studiów nad Dziennikarstwem Reutersa w Oksfordzie, wskazały jednoznacznie, że telewizja stanowi główne źródło informacji zarówno dla Europejczyków, jak i dla przedstawicieli innych kontynentów (61\% Fancuzów, 56\% Niemców, 50\% Brytyjczyków, 50\% Amerykanów, 54\% Japończyków) ${ }^{1}$. Magazyny wiadomości pozostają podstawowym źródłem informacji dla wszystkich grup wiekowych poza najmłodszymi (18-24 lata) - ci wskazali internet jako źródło dominujące. W prezentowanym raporcie nie odnoszono się do polskich doświadczeń, jednak pośrednio wyniki $z$ innych krajów europejskich potwierdzają tegoroczne badania CBOS, dotyczące co prawda kwestii bardziej szczegółowych, jednak umożliwiających wnioskowanie w szerszej perspektywie. Na pytanie: „Skąd przede wszystkim czerpie Pan(i) informacje na temat kandydatek i kandydatów w wyborach do Parlamentu Europejskiego?" najliczniejsza grupa $42 \%$ badanych Polaków odpowiedziała, że z programów informacyjnych i publicystycznych w telewizji. Można więc wysnuć wniosek, że telewizja, w tym magazyny wiadomości, pozostają podstawowym źródłem informacji współczesnego odbiorcy (w tym samym badaniu internet wskazało $31 \%$, prasę $29 \%$, a radio $19 \%)^{2}$. Inne badanie, dotyczące wiarygodności programów informacyjnych i publicystycznych, przeprowadzone przez CBOS w 2012 roku, wykazało, że zaufanie Polaków do trzech największych nadawców

${ }^{1} \mathrm{http}$ ://www.digitalnewsreport.org/survey/2014/frequency-of-access-and-interest-in-news-2014/, (dostęp: 21 października 2014).

2 http://www.csw.umk.pl/komunikatcboscsw (dostęp: 23 czerwca 2014) (komunikat nr 65/2014 z badań CBOS pt. „Polacy o proponowanych zmianach w prawie wyborczym”, Warszawa, maj 2014). 
(TVP, TVN, Polsat) kształtuje się na zbliżonym poziomie ok. 3,6 w skali od 1 do 5 (gdzie „1" oznaczało, że są niewiarygodne, a ,„”, że zasługują na zaufanie) ${ }^{3}$.

Mimo niezaprzeczalnego wpływu telewizyjnych newsów na funkcjonowanie społeczeństwa nie cieszą się one szczególnym zainteresowaniem polskich lingwistów, którzy (jeśli podejmują badania na ten temat) koncentrują się na wybranym, wąskim aspekcie ${ }^{4}$, nieliczne próby całościowej charakterystyki mają charakter medioznawczy (Godzic 1999, 2004; Palczewski 2009, 2011, 2013). Naszym celem będzie wskazanie kilku kierunków przemian polskiego newsa - gatunku będącego strukturą tyle tradycyjną i dobrze osadzoną w medialnej genologii, ile dynamiczną i ulegającą transgresjom. Zmiany mogą należeć do rewolucyjnych radykalnych, gwałtownych, przewartościowujących zastaną rzeczywistość, lub do ewolucyjnych, a zatem przewidywalnych, płynnych, sukcesywnych.

Istotna w tym miejscu może być perspektywa - nadawcza oraz odbiorcza. $Z$ jednej strony nadawcy, mając świadomość swojego oddziaływania na audytorium oraz pewność, że ich komunikat jest jednym z wielu możliwych do wyboru, tak konstruują przekazy, by odbiorcę zatrzymać przy swoim produkcie. Zmiany te dotyczą — jak się nam wydaje - programu informacyjnego jako całości, w mniejszym stopniu samego newsa telewizyjnego. W obszarze makrogatunku, jakim jest magazyn wiadomości, w jego układzie, hierarchizacji newsów oraz sposobie ich prezentacji zauważamy dość rewolucyjne przemiany, z kolei w ramach badań samych newsów, na poziomie konkretnych realizacji zmiany są łagodniejsze. $Z$ drugiej strony być może to rutynowe procedury odbiorcze pomogą wskazać, czy mamy do czynienia z realizacją ewolucyjna lub rewolucyjna, czy odbiorca na podstawie dotychczasowych realizacji gatunkowych ma możliwość oszacowania istotności, prawdziwości, kompletności dostarczanych mu danych.

\section{Rewolucja}

Rewolucja zakłada gwałtowną zmianę, której cofnięcie jest niemożliwe. Nie jest zatem możliwy powrót do rzeczywistości przedrewolucyjnej, przewrót odmienia bowiem mentalność ludzi i sposób pojmowania przez nich świata. Taki nagły zwrot powoduje przemiany w społeczeństwie, gospodarce, polityce, w układzie sił rządzących, sprawia, że odmienia się kultura oraz — co dla naszych badań najistotniejsze - do nowych warunków adaptuje się także komunikacja i jej przepływy. W nowym układzie kanały komunikacyjne i sposoby formułowania wypowiedzi muszą się niejako na nowo sfunkcjonalizować, przeistoczyć, by spełniać zadania wyznaczone przekazom w porewolucyjnej sytuacji. Szczególne zadania wyznacza

3 http://www.cbos.pl/SPISKOM.POL/2012/K_150_12.PDF (dostęp: 14 maja 2014).

4 J. Janus, A. Kudra, M. Poprawa, B. Sobczak, K. Wardzała. 
się więc mediom, a w nich informacjom, które niosą wiedzę o świecie lokalnym, znanym, bliskim, ale też mniej i bardziej odległym, egzotycznym i obcym.

W polskiej przestrzeni polityczno-społeczno-kulturowej odniesienie do rewolucji może mieć co najmniej dwie znaczące płaszczyzny, wywodzące się z różnych porządków definicyjnych. Po pierwsze można mówić o roku 1989 i zmianach z nim związanych (Okrągły Stół, wybory, nowa legitymizacja władzy, otwarcie się na świat), zmianach bezkrwawych i pokojowych, które miały moc wydarzeń iście rewolucyjnych. Od tego roku Polska powróciła do nurtu przemian kulturowych europejskich i światowych, z którymi wiąże się druga płaszczyzna rewolucyjnego odniesienia - mamy tu na myśli postępujące procesy globalizacyjne wiążące się z pojęciem rewolucji technologicznej. I choć telewizja nie jest przekaźnikiem nowym, to upowszechnienie internetu oraz rozwój sprzętu audiowizualnego dały impuls do przemian także w obrębie tego medium. Streamingi, podcasty, aplikacje na telefony oraz inne nowoczesne rozwiązania technologiczne sprawiły, że informacja stała się produktem, którego wytwórcy konkurują z sobą o uwagę odbiorcy-klienta. A ten może wybierać pomiędzy tradycyjną ofertą informacyjną a nowoczesnymi technologicznie możliwościami.

Badając przekazy informacyjne w polskiej telewizji w kontekście zmian rewolucyjnych, należy zwrócić uwagę na kilka zagadnień. Należą do nich kwestie ogólne związane z budową magazynów wiadomości, sposobami uwiarygodniania przekazu przez nadawców, budowaniem zaufania do programu (co zwykle łączy się z wyborem z oferty tego konkretnego medium oraz kształtuje nawyk odbiorczy - siłę niezwykle mocno dziś akcentowaną) czy wreszcie powiązanie informacji z funkcją rozrywkową i obudowanie przekazu konotacjami tradycyjnie zarezerwowanymi dla innych typów przekazu (np. dla dziennikarstwa interwencyjnego). Wydaje się, że najgwałtowniejszą zmianę na polskim rynku magazynów wiadomości spowodowała redefinicja istoty tego typu programów i samych newsów wyrażona w trakcie realizacji „Faktów” w telewizji TVN. Autor tej nowej koncepcji, Tomasz Lis, wykłada ją następująco: „obiektywizm nie polega na tym, żeby przedstawić dokładny obraz świata, ale żeby pokazać wszystko, co ważne i ciekawe. [...] [N]ie mniejszą wagę niż informacja o nagim fakcie, czyli odpowiedź na pytania: kto? co? gdzie? kiedy? jak? - ma oddanie atmosfery zdarzeń, klimatu, nastroju ludzi, społeczno-historycznego kontekstu tego, co się dzieje" (Lis 2004, s. 48). Tę zmianę dostrzega się na poziomie makro i na płaszczyźnie konkretnych newsów.

Konstrukcja interesujących nas audycji przeszła najgwałtowniejszą chyba przemianę, ostatnie lata przynoszą bowiem odejście od układu statycznego, z prezenterem usadzonym nieruchomo przy stole, na rzecz dynamicznego ustawienia i poruszania się prowadzącego w studiu. Sama koncepcja przestrzeni, z której emituje się program informacyjny, jest przemyślana w każdym szczególe podobnie jak dominująca kolorystyka, a nawet poziomy podłogi czy atrybuty, w które wyposażony jest prezenter (kartki, długopis, tablet, sprzęt komputerowy). 
Są one nośnikiem dodatkowych konotacji - ma być obiektywnie, nowocześnie, szybko, dziennikarz jest w ciągłym kontakcie z doniesieniami agencji informacyjnych, ma sprawiać wrażenie najlepiej poinformowanej osoby. Jednak — jak wskazują ustalenia medioznawcze — „złudne jest przekonanie o wiadomościach jako obiektywnej reprodukcji społecznej i politycznej rzeczywistości. Są [one] natomiast strukturą wysoko kodowanych przekazów, kształtowanych przez kompleksowe serie kodów pochodzących z ekonomicznych, ideologicznych i kulturowych warunków ich produkcji" (Godzic 1999, s. 85).

Zdynamizowanie samego sposobu prezentowania newsów łączy się także z innym aspektem organizacji przestrzeni - wyjściem poza studio, w teren, w którym miały miejsce określone wydarzenia. Programy informacyjne realizuje się więc z dachów wysokich budynków, z których dobrze widać miejsce zdarzenia, z ulicy, sprzed zawalonego budynku itp. Prezenter często narażony jest na zmienną aurę, moknie więc lub marznie. To czyni przekaz autentyczniejszym, prowadzący program niejako zbliża się do odbiorcy, zatracony zostaje dystans wywołany przestrzenią studia telewizyjnego. Unaocznienie miejsc wydarzeń powiązać należy z pojęciem wiarygodności, w tym akurat przypadku budowanej na wrażeniu bezpośredniej obserwacji, bycia na miejscu, bycia świadkiem lub nawet uczestnikiem wydarzeń. Przekaz taki ma mieć proste przełożenie: jesteśmy tu, gdzie dzieją się rzeczy ważne (w Rzymie w dzień kanonizacji Jana Pawła II, w Kijowie podczas ukraińskich protestów, w Katowicach — w miejscu, gdzie w wyniku wybuchu gazu runęła kamienica itp.). Ta mobilność zarezerwowana była niegdyś jedynie dla reporterów, teraz przenosi się cała ekipa realizująca program, by dać widzowi ułudę współuczestniczenia w zdarzeniach i współobecności. Obraz poręcza prawdę, poświadcza prawdziwość zdarzeń, dokumentuje.

Siłę przekazu wzmacnia dialogiczny model komunikowania z widzami, oparty na bezpośrednich sposobach zwracania się do widza oraz budowania z nim bliskich relacji poprzez kontakt wzrokowy. „Całą swoją osobą, doświadczeniem zawodowym i rzetelnością, prezenter potwierdza wiarygodność przekazywanych informacji” (Allan 2006, s. 97). Prezenter patrzy widzowi w oczy, wydaje się, że to kontakt szczery i bliski, jeśli natomiast uwzględni się wiedzę o technologicznym aspekcie powstawania tych przekazów - wtedy natychmiast uruchamiają się skojarzenia z odległego pola - przecież prezenter patrzy w kamerę, do niej mówi i do niej się uśmiecha, jest to zatem komunikacja sztuczna, aktorska, wyćwiczona, wypracowana. Jednocześnie jednak „obraz medialny narzuca określony porządek poznawczy konstytuujący swoistą »epistemologię widzialności«" (Wilk 2002, s. 297).

Trzeba wszak zauważyć, że odbiór telewizyjnych magazynów wiadomości jest odbiorem, który może przybierać rozmaite modele ${ }^{5}$, może stać się m.in. dzia-

5 Inne opisywane w literaturze przedmiotu modele to telewizja jako złodziej czasu, szum tła, element jednoczący wspólnoty, organizator życia towarzyskiego (por. Halawa 2006; Bogunia-Borowska 2012). 
łaniem zrutynizowanym, noszącym znamiona rytuału, dającego widzom poczucie kontroli nad rzeczywistością, potwierdzającego schematy poznawcze, właśnie utwierdzającego, a nie wprowadzającego zmiany, nie różnicującego (por. Halawa 2006; Bogunia-Borowska 2012). Oglądanie magazynów informacyjnych jest wpisane w porządek dnia, stanowi zwyczaj oparty na tradycji rodzinnej, organizuje czas domowy, segmentuje dobę. W końcu telewizyjny dziennik z najważniejszymi wiadomościami ukazuje się o godzinie 19.30 od 1965 roku! Ta sama pora i podobny kształt przekazu dają widzowi „poczucie ontologicznego bezpieczeństwa" (Giddens 2003, s. 205).

Dlatego tak ważna staje się struktura magazynu, układ następujących po sobie newsów i elementów wprowadzających poszczególne materiały. I znowu współcześnie mamy do czynienia z odmienionym sposobem prezentacji, nie bezosobowe, suche zapowiedzi, ale narracja, opowiadanie, które ma wciągnąć odbiorcę w przekaz. A zatem prezenter wprowadza nowe wątki, segmentując przekaz, delimituje poszczególne fazy programu, sprawia, że nadawane w odpowiedniej kolejności newsy stanowią zwartą, koherentną całość. Składa się ona na pewną wizję rzeczywistości, w której przeważają odczytania aprobowane przez kulturę dominującą.

Ponieważ kształt programu informacyjnego nie jest jednorodny tematycznie, a każdy kolejny news dotyczy odmiennej sprawy, jednostkami spajającymi całość są właśnie wypowiedzi wygłaszane przez prowadzącego. Ich rolą jest porządkowanie przebiegu komunikacji z odbiorcami, wprowadzanie ich w nowe konteksty narzucane przez kolejne wiadomości, segmentowanie struktury magazynu. Segmentacja ta przebiega zwykle w osi: faza otwarcia-materiał, czasami po nim następuje też faza zamknięcia prezentacji materiału. Faza otwarcia jest zapowiedzią, pełni więc funkcję wprowadzenia, ma zainteresować widza newsem, zaintrygować (toteż często pojawiają się tu pytania, wątpliwości, które news ma rozwiać). Faza zamknięcia (jeśli jest) kończy prezentację newsa podsumowaniem, komentarzem, puentą, polemiką. W schemacie ogólniejszym narracja prowadzącego ma przykuć uwagę widza i podtrzymać ją, stąd wielokrotnie prezenter ustala przebieg programu, przypominając o kolejności tematów oraz zapowiadając, co jeszcze w programie będzie można zobaczyć.

Prezenterska narracja wplata poszczególne newsy w konstrukcję ogólną, której podporządkowana jest koncepcja programu mającego spełniać wiele rozmaitych funkcji - od informacji po rozrywkę. Widz zatem ma mieć wrażenie, że panuje nad rzeczywistością, że jest poinformowany, wie, co się dzieje, ale oprócz tego ma być jeszcze rozbawiony, poruszony, oburzony, wzruszony, ma odczuwać chęć zaangażowania się w określone działania itp. Dlatego też trzeba przyjrzeć się układowi newsów w magazynie. Hierarchia wiadomości nie jest bowiem dana czy ustalona na stałe. Magazyny wiadomości odchodzą od prezentacji jako prymarnych spraw związanych z polityką czy ekonomią, wyeksponowane stają się współcześnie ludzkie sprawy, tematy związane z konkretnymi ludźmi, bohaterami 
przedstawionymi z imienia i nazwiska. Nawet gdy newsy dotyczą zagadnień szerszych, to zwykle punktem wyjścia jest przykładowy człowiek, którego w jakiś sposób to zagadnienie dotyczy (np. gdy rośnie kurs franka szwajcarskiego, pokazuje się widzom Jana Kowalskiego, któremu wzrośnie rata kredytu itp.).

Wydaje się, że mamy tu do czynienia ze swoistymi modami. Rzecz jest na tyle intrygująca, że wymaga osobnego opracowania, a tu jedynie możemy problem zasygnalizować. Współcześnie najmodniejsze wydają się materiały dotyczące zwykłych ludzi i ich problemów - zwłaszcza związanych ze zdrowiem (rzadkie choroby, ciężki przebieg leczenia, drogie kuracje, kosztowna rehabilitacja), sprawami bytowymi (warunki życia, sytuacja materialna) lub opieką nad dziećmi (dzieci niepełnosprawne, rodziny wielodzietne, rodziny zastępcze, domy dziecka itp.). Wiele z tych przekazów tradycyjnie było włączanych do programów z zakresu dziennikarstwa interwencyjnego, którego zadaniem jest reagować na niesprawiedliwość społeczną, wskazywać zaniedbania władz oraz przestrzegać. Podstawowym wyznacznikiem takich materiałów jest empatyczna postawa dziennikarza, odznaczającego się wrażliwością na krzywdę innych, oraz wiara w siłę mediów. Ton tych newsów jest łzawy, rzewny, wzruszający — na poziomie narracji i obrazowania, trzeba też podkreślić, że takie przedstawienie nie zawsze jest ujmowane w ramie ograniczeń czy uwarunkowań kulturowych. Niegdyś nie znalazłyby one miejsca w magazynie informacyjnym, a współcześnie są niemal w każdym wydaniu i niekoniecznie na końcu przekazów.

Rewolucyjne jest bez wątpienia sprzęgnięcie magazynu wiadomości tradycyjnie pełniącego funkcje powiadamiania z funkcją rozrywkową. W. Godzic, pisząc o prezenterach magazynów wiadomości, nazywa ich „wodzirejami” (Godzic 2002, s. 97), wskazując na ich nowe zadania. Tradycyjnie wodzireje dbają o dobrą zabawę, aktywizują jej uczestników, organizują przebieg imprez taneczno-muzycznych. Podobnie prezenterzy - są nie tylko dysponentami informacji, ale też emocji, nastrojów. Newsy utkane w ich narrację zyskują wymiar subiektywny, wskazuje się na atmosferę, wykraczając poza wymiar faktograficzny.

\section{Ewolucja}

Gdy przyjrzeć się podstawowym, wynikającym ze specyfiki medium audiowizualnego właściwościom, można zauważyć, że podstawowe wyznaczniki newsa telewizyjnego (funkcjonowanie w makrogatunkowym schemacie, montaż, biała, zielona, setki, wielokodowość itp.) nie zmieniły się od emisji pierwszego „Dziennika Telewizyjnego” w 1958 roku. Jak zauważa M. Lisowska-Magdziarz, „paradygmat gatunkowy komunistycznego dziennika telewizyjnego nie różnił się zasadniczo od tego, po czym i dzisiaj rozpoznajemy serwis informacyjny. I tutaj, jak na Zachodzie i w USA, mieliśmy zbiór wiadomości, pogrupowanych te- 
matycznie i według ważności, odczytywanych przez prezentera lub prezenterów w beznamiętny sposób i krótko komentowanych; prezenter lub prezenterzy usytuowani byli w studiu telewizyjnym, umiejscowieni frontem do widza; informacje odczytywane $\mathrm{w}$ studiu pojawiały się na zmianę $\mathrm{z}$ informacjami wizualnymi w postaci krótkich filmów dokumentalnych czytanych z offu" (Lisowska-Magdziarz 2008, s. 169). Możliwość rozpoznania paradygmatu gatunkowego to jednak za mało, by wyciągnąć wnioski o stałości genologicznej magazynu wiadomości. Wskazałyśmy już kilka obszarów, które mimo tych generalnych sygnałów podobieństwa objęte zostały iście rewolucyjnymi zmianami. Czas na zanotowanie paru kategorii, które przeszły procesy bardziej płynne, mniej jednoznaczne w swoim wymiarze. Jedną z kategorii zmieniających się ewolucyjnie jest, naszym zdaniem, wpisana w charakterystykę newsa aktualność.

Aktualność, oznaczająca odniesienie do teraźniejszości, obowiązywanie w danej chwilií, stanowi jedną z właściwości decydujących o wiarygodności newsa. Istotą newsowości jest (wynikające także z etymologii słowa news) szybkie docieranie do odbiorcy z informacjami nowymi i możliwie kompletnymi - fundamentem gatunku wydaje się przekonanie nadawcy, że odbiorca jeszcze nie wie o danym fakcie lub też jest poinformowany w sposób szczątkowy i chciałby te dane uzupełnić, potwierdzić, zweryfikować. Konkurencja między nadawcami, zarówno w granicach jednego medium — telewizji, jak i poza nimi, wiąże się również z koniecznością bycia pierwszym, przekonania widza o możliwie największej aktualności przekazywanych informacji. Cenne i wiarygodne dla widza staje się śledzenie przekazu live - wrażenie uczestnictwa w tym, co jest pokazywane na ekranie, potęguje odbiorcze przekonanie o byciu na bieżaco. Mechanizm „,ideologii przekazu na żywo” wskazuje Lisowska-Magdziarz: „Poczucie natychmiastowości osiągane jest poprzez odwołanie się do prostych konwencji nadawczo-odbiorczych. Jedna z tych konwencji zakłada, że jeśli dziennikarz nadaje na żywo, to donosi o czymś nadzwyczaj aktualnym. Nawet jeśli akurat nadaje on live z miejsca, gdzie wydarzenia już się skończyły, z komentarzem »to tu, właśnie, proszę państwa, jeszcze wczoraj rano«" (Lisowska-Magdziarz 2008, s. 153). Zbigniew Bauer zauważa również związek między aktualnością a prawdziwością przekazu w odbiorczej perspektywie: „Coraz wyraźniej okazywało się, że za »prawdziwe« uznaje się jedynie to, co dociera do publiczności bezpośrednio, równocześnie z przebiegiem zdarzenia" (Bauer 2009, s. 63). Aktualność konotuje i wzmacnia również używanie w newsie czasu teraźniejszego, określonych okoliczników czasu („teraz”, „w tej chwili”, „kilka sekund temu") czy partykuł.

Aktualność podlega ewolucji nie tylko $\mathrm{w}$ związku z zawężającym się coraz bardziej na osi czasu fragmentem oznaczającym to, co stanowi odniesienie do teraźniejszości - warto ją rozpatrywać także w odniesieniu do dwóch innych kategorii, dostrzeżonych w newsie telewizyjnym: preaktualności oraz ponadaktu-

${ }^{6}$ http://sjp.pwn.pl/sjp/aktualny;2549278 (dostęp: 29 listopada 2014). 
alności. Preaktualność oznacza funkcjonowanie „przed czasem”, medialne oczekiwanie na to, co się zdarzy — oczekiwanie wspólnie z widzami, których zachęca się do uczestniczenia $\mathrm{w}$ tym procesie (jest to kategoria silnie związana ze wskazanym wyżej zjawiskiem śledzenia przez widza przekazu w wersji na żywo). Preaktualność odnosi się najczęściej do zdarzeń, faktów, zjawisk, na które czekamy (ponieważ wynikają z kalendarza albo były wcześniej zapowiedziane, np. wyniki wyborów prezydenckich, decyzja o składzie nowej Rady Europejskiej itp.), lub takich, które są nagłe, wyjątkowe i przełomowe (katastrofa lotnicza, trzęsienie ziemi). Rosnąca popularność informacji przekazywanych w trybie breaking news wymaga budowania narracji nie tylko o tym, co się zdarzyło lub zdarza, lecz także o tym, co się jeszcze stanie: pojawia się w newsie czas przyszły oraz tryb przypuszczający, przedstawiający widzowi możliwe scenariusze nadchodzących wydarzeń. Nie bez wpływu na konstrukcję newsa jest większa niż przeciętna redundancja takich przekazów - dziennikarz poszukuje tematów zastępczych, pobocznych, często również powtarza to, co już zostało przekazane. Newsy o znamionach preaktualności przeorganizowują także strukturę magazynu wiadomości - często taki news jest podzielony na segmenty i pojawia się w kilku miejscach magazynu, potęgując tym samym atmosferę oczekiwania. Natomiast ponadaktualność to kategoria obserwowana $\mathrm{w}$ newsach umieszczanych $\mathrm{w}$ dalszych częściach magazynów wiadomości, występujących jednak w znaczącej liczbie nie tylko w sezonie wakacyjnym czy świątecznym. Dotyczy materiałów, które funkcjonują niejako poza czasem, a tym samym nie mogą się przeterminować (w odniesieniu do dystansu czasowego cechującego dzisiejsze media), ich emisja jest możliwa w każdym momencie w roku (np. materiał o zabawnych, dwuznacznych nazwach miejscowości w Polsce czy o muzycznych gustach polityków) lub w określonym sezonie (np. materiał o nielegalnym wycinaniu lasów w czasie przedświątecznym). Ponadaktualność często łączy się ze zjawiskiem inforozrywki czy z kategorią socjonewsa, opisaną m.in. przez Małgorzatę Bogunię-Borowską (2007, s. 341-351).

Wydaje się, że proces przygotowania newsa (w tym również etap gromadzenia informacji) podlega naturalnym, płynnym przekształceniom ze względu na rozwój technologii, zjawiska mediatyzacji, konwergencji — współistnienie wielu mediów proponujących odbiorcy dane na ten sam temat musi zakładać zwiększenie tempa zdobywania informacji i ich obróbki. W tym kontekście można mówić zarówno o swoistej komplementarności mediów (np. telewizji i internetu), jak i o ich kanibalizacji (Ćwieluch 2011, s. 22-24), sprzyjającej powstaniu zamkniętego kręgu omawianych przez media zdarzeń, bohaterów, miejsc, homogenizacji tematów pojawiających się w obiegu. Pierre Bourdieu zauważa: „Wskaźnik oglądalności wpływa na telewizję w pewien szczególny sposób: przekłada się na presję czasu. Konkurencja między gazetami, konkurencja między gazetami a telewizją, konkurencja między telewizjami - wszystko rozgrywa się na płaszczyźnie czasowej [...]. Chodzi o to, żeby być pierwszym" (Bourdieu 2011, s. 55). W związku ze zmianą tempa procesu informowania na uwagę zasługują przynajmniej dwie 
kwestie: jasnego rozgraniczenia między przekazem dziennikarskim a przekazem z zakresu PR oraz aktywizowania odbiorców do działań reporterskich.

Pierwsze zagadnienie wynika z faktu, iż czynności wykonywane przez dziennikarza w procesie przygotowania newsa są obserwowane przez odbiorców tylko w niewielkim stopniu, najczęściej na etapie ostatnim — zapoznawania się z ostatecznym efektem (wyemitowanym newsem). Działania wcześniejsze (pozyskiwanie danych, dywersyfikacja źródeł, obróbka informacji, montaż itp.) są dla telewidzów niewidoczne ${ }^{7}$. Może to sprzyjać zjawiskom, których odbiorca nie jest w stanie dostrzec i ocenić: zacieśnianiu się relacji dziennikarz-PR-owiec, koncentrowaniu się dziennikarza (ze względu m.in. na presję czasu) na przetwarzaniu, a nie zbieraniu informacji, co sprzyja większej aktywności specjalistów z zakresu PR w podsuwaniu tematów istotnych $\mathrm{z}$ ich punktu widzenia. Niebagatelne znaczenie ma również fakt, iż wielu pracowników branży PR to byli dziennikarze ${ }^{8}$. Dwa poniższe przykłady realizacji, budzących wątpliwości związane z doborem źródeł i sposobami ich wykorzystania, są jedynie reprezentacją większej liczby materiałów wpisujących się w podobny schemat. Pierwszy news „Szlachetna Paczka - idą święta"9 został poświęcony kwestii przedświątecznego pomagania ubogim rodzinom; w materiale mówi się o dwóch akcjach: „Szlachetna Paczka” stowarzyszenia „Wiosna” oraz (w tle) „Podaruj Misia” fundacji „TVN — nie jesteś sam”. Drugi przykładowy news, zatytułowany „Biblioteka w telefonie"10, zawierał informacje o nowatorskich sposobach zachęcania do czytania - w dwuipółminutowym materiale znalazły się informacje o dwóch pomysłach: o aplikacji mobilnej Czytaj KRK! (realizowana przez Krakowskie Biuro Festiwalowe i Woblink, polską platformę e-bookową) oraz o muralu Fundacji Sztuki Nowej „Znaczy się". W obu przypadkach zastanawiający wydaje się dobór źródeł, funkcjonujących już nie tylko jako egzempla do zobrazowania określonego zjawiska, lecz wyeksponowanych na tyle silnie, by odbiorca zainteresował się działalnością tych konkretnych podmiotów, a nie problemem przedstawionym w newsie (działalnością organizacji pomagających ubogim czy tych, które promują czytelnictwo).

Zmiana tempa nadawania przekłada się również na działania redakcji, które zachęcają odbiorców do reporterskiej aktywności. Oto jeden z tekstów, kierowanych do amatorów chcących dzielić się materiałami i spostrzeżeniami o tym, co się wokół nich dzieje: „Martwisz się, że nie masz profesjonalnego sprzętu? Nic

7 O modelu tzw. góry lodowej w odniesieniu do działań z zakresu public relations pisze S. Black (1999); model ten opisuje w odniesieniu do środowiska dziennikarskiego W. Jabłoński (2007, s. 72-75).

8 W tygodniku „Polityka” możemy odnaleźć swoistą środowiskową autoanalizę: „Ludzie, którzy kiedyś pracowali w mediach, dziś za pieniądze korporacji sami karmią je informacjami, budują wizerunki, dbają o przekaz, wzmacniają markę. Produkcja newsa poza mediami to już wielka infrastruktura, żyjąca w symbiozie z dziennikarzami” (Ćwieluch 2011, s. 24).

9 TVN, „Fakty” 25 listopada 2014.

10 Polsat, „Wydarzenia” 29 listopada 2014. 
nie szkodzi! Nie wiesz, czy Twój temat jest interesujący? To nic! Będziemy z Tobą szczerzy: stworzenie dobrego newsa czasem wymaga po prostu szczęścia. Załóżmy więc, że znalazłeś się w miejscu, w którym dzieje się coś ciekawego, coś, czym chciałbyś się podzielić z innymi..."11. Zmienia się zatem zadanie odbiorcy: z pozycji konsumenta, obywatela, weryfikatora, recenzenta, wreszcie uczestnika przechodzi do roli nadawcy. Wiąże się to bez wątpienia z nowymi zadaniami, których odbiorca stający się nadawcą nie musi rozumieć - może być przekonany, że spojrzenie z perspektywy przeciętnego Kowalskiego jest wartościowsze niż znajomość mechanizmów społecznych czy szersza wiedza. Pozostaje jeszcze kwestia odpowiedzialności za przekaz, złudzenie partnerstwa w relacji nadawczo-odbiorczej może spowodować, że „rządy odbiorców” odwrócą się przeciwko nim. Publikacja amatorskiego materiału (tekstu, fotografii, filmu) w przestrzeni internetowej, na stronie renomowanego nadawcy może być pierwszym krokiem na drodze do zmiany kształtu serwisu telewizyjnego — dziennikarze i reporterzy niejednokrotnie wykorzystują amatorskie przekazy, by obudować lub uzupełnić swój materiał. Pojawienie się internetu jako przestrzeni, która może pomieścić wiele, zmieniło układ sił. „Internet nie jest medium »zdawania sprawy«, ale przestrzenią dawania świadectwa. Pozwala komunikować doświadczenie i doświadczać" (Bauer 2009, s. 232). Pojawia się pytanie, czy proces wzajemnego przenikania się mediów, rozwój swoistej komplementarności wielu przekazów wpłyną na genologiczne właściwości telewizyjnego newsa. A raczej zapytać należy, czy ten wpływ okaże się zmianą ewolucyjną, czy rewolucyjną.

\section{Bibliografia}

Allan S. (2006), Kultura newsów, przeł. A. Sokołowska, Kraków.

Bauer Z. (2009), Dziennikarstwo wobec nowych mediów. Historia, teoria, praktyka, Kraków.

Black S. (1999), Public relations, Warszawa.

Bogunia-Borowska M. (2007), Polskie strachy, [w:] Czego obawiają się ludzie?, red. M. Libiszowska-Żółtkowska, Warszawa.

Bogunia-Borowska M. (2012), Fenomen telewizji. Interpretacje socjologiczne i kulturowe, Warszawa. Bourdieu P. (2011), O telewizji. Panowanie dziennikarstwa, przeł. K. Sztandar-Sztanderska, A. Ziółkowska, Warszawa.

Ćwieluch J. (2011), Skąd się bierze news?, „Polityka”, nr 32.

Giddens A. (2003), Stanowienie społeczeństwa. Zarys teorii strukturacji, przeł. S. Amsterdamski, Poznań.

Godzic W. (1999), Telewizja jako kultura, Kraków.

Godzic W. (2004), Telewizja i jej gatunki. Po Wielkim Bracie, Kraków.

Halawa M. (2006), Życie codzienne z telewizorem. Z badań terenowych, Warszawa.

Jabłoński W. (2007), Kreowanie informacji. Media relations, Warszawa.

Lis T. (2004), Co z tym dziennikarstwem?, rozmowa z Krystyną Strączek, „Znak”, nr 593.

11 http://kontakt24.tvn24.pl/poradnik-dla-reportera.htm (dostęp: 29 listopada 2014). 
Lisowska-Magdziarz M. (2008), Media powszednie. Środki komunikowania masowego i szerokie paradygmaty medialne w życiu codziennym Polaków u progu XXI wieku, Kraków.

Palczewski M. (2009), Definicje i koncepcje newsa w tradycji anglosaskiej. Przegląd i próba klasyfikacji, ,Studia Medioznawcze”, nr 3.

Palczewski M. (2011), Prawda o newsie. Definicja — granice poznania — konteksty, [w:] Teorie komunikacji i mediów 4, red. M. Graszewicz, J. Jastrzębski, Wrocław.

Palczewski M. (2013), Tweet jako odmiana newsa czy nowoczesny (ponowoczesny) gatunek dziennikarski?, „Nowe Media”, nr 4.

Wilk E. (2002), Ekrany pisma czy ekrany widzialności, [w:] Wiek ekranów, red. A. Gwóźdź, A. Zawojski, Kraków.

\section{Strony internetowe}

http://kontakt24.tvn24.pl/poradnik-dla-reportera.htm (dostęp: 29 listopada 2014).

http://sjp.pwn.pl/sjp/aktualny;2549278 (dostęp: 29 listopada 2014).

http://www.cbos.pl/SPISKOM.POL/2012/K_150_12.PDF (dostęp: 14 maja 2014).

http://www.csw.umk.pl/komunikatcboscsw (dostęp: 23 czerwca 2014) (komunikat nr 65/2014 z badań CBOS pt. „Polacy o proponowanych zmianach w prawie wyborczym”, Warszawa, maj 2014).

http://www.digitalnewsreport.org/survey/2014/frequency-of-access-and-interest-in-news-2014/ (dostęp: 21 października 2014).

\section{Revolution or evolution? Transformation of TV news report}

\section{Summary}

We would like to analyze TV news report. This term is frequently used, the researchers do not specify which charakteristics of this genre are the most specific and essential. We understand news as a component of television newscast, regularly scheduled TV program. The form of the news bulletin is apparently unchanged because the sending-receiving mechanisms are constant, with telegenic newscasters, a properly arranged studio, two-, three-minute long news reports, and the roles the spectators are cast in. These tricks, however, only serve the senders' strategies, which make it necessary to define the television news report in a dynamically changing media reality. Since the genre is an open and dynamic structure and seamlessly adapts to current needs, it is possible to approach it "diachronically" and present its evolution — mild, fluid, predictable change, and revolution — radical, abrupt change.

Keywords: television, news bulletin, TV news report, genre 